\title{
Photoresponse of a highly-rectifying 3C-SiC/Si heterostructure under UV and visible illuminations
}

\author{
Abu Riduan Md Foisal, Toan Dinh, Philip Tanner, Hoang-Phuong Phan, Tuan-Khoa Nguyen, Erik W. Streed, and \\ Dzung Viet Dao
}

\begin{abstract}
In this study we report the photo-characteristics of an $\mathrm{n}-3 \mathrm{C}-\mathrm{SiC} / \mathrm{p}-\mathrm{Si}$ heterojunction under ultraviolet and visible illuminations. The $3 \mathrm{C}-\mathrm{SiC}$ thin film has been grown on $\mathrm{Si}$ (100) substrate by a Low Pressure Chemical Vapor Deposition (LPCVD) technique at $1000{ }^{\circ} \mathrm{C}$. The as-grown structure shows an excellent rectification ratio $\left(I_{F} / I_{R}\right)$ of $1.8 \times 10^{6}$ at $\pm 2 \mathrm{~V}$ and a reverse bias current of $5.5 \times 10^{-9} \mathrm{~A}$ at $2 \mathrm{~V}$ in dark conditions. The heterojunction exhibits good sensitivity simultaneously to both UV $(375 \mathrm{~nm})$ and visible $(637 \mathrm{~nm})$ illuminations. The results indicate that the fabricated structure could be an excellent platform where detection of a wide spectral illumination is vital. The insight of electron-hole pairs generation and carrier transport mechanism at different illumination conditions is explained in detail via an anisotype heterojunction energy band diagram.
\end{abstract}

Index Terms-3C-SiC/Si heterojunction, rectification ratio, UV-visible illumination, responsivity, energy band diagram.

\section{INTRODUCTION}

A Photodetector with high sensitivity and reliability over wide-spectral regions is highly essential for many applications such as full color sensors, multispectral image sensors, and switches [1], [2]. The photodetectors, which consists of only one semiconductor material (such as $\mathrm{ZnO}, \mathrm{GaN}$, and $\mathrm{Si}$ ), absorb the photons which have higher energy than the bandgap of that material. This property limits their applications in wide spectral sensitivity devices. The advancement in technology and device fabrication processes makes it possible to develop heterostructure based multiband photodetectors for detecting both UV-visible light using the appropriate combination of different materials ( $\mathrm{n}-\mathrm{ZnO} / \mathrm{p}-\mathrm{Si}$ [3], $\mathrm{ZnO}-\mathrm{CdS}$ [1], and a-SiC/a$\mathrm{Si}[4])$. In these structures, a large bandgap material is used as a top layer, hence low-energy photons in the visible range pass through the top layer and are absorbed in the bottom narrower band semiconductor material. Therefore, the strategy of using heterostructure enhances the absorption of both UV and visible photons, which leads to increased device sensitivity.

Silicon carbide $(\mathrm{SiC})$ is one of the most favorable wide bandgap semiconductor materials owing to its superior mechanical and electrical properties, as well as high resistance to thermal and chemical stress [5], [6]. Among 200 polytypes of $\mathrm{SiC}$, only $3 \mathrm{C}$ polytype can be grown epitaxially on a large Si-substrate at around $1000^{\circ} \mathrm{C}$ and hence the cost of the wafer reduces significantly [7], [8]. By taking the advantages of silicon-orientated mature MEMS processing technologies, 3C$\mathrm{SiC}$ on the $\mathrm{Si}$ structure has opened a new platform to develop a wide range of better and low cost highly sensitive physical sensors for harsh environments.

A. R. M. Foisal, T. Dinh, P. Tanner, H.-P. Phan, T.-K. Nguyen, and D. V. Dao are with the Queensland Micro-Nanotechnology Centre, and E. W. Streed is with the center of Quantum Dynamics, Griffith University, Nathan QLD 4111, Australia. (e-mail: ar.mdfoisal@ griffithuni.edu.au).
Although the best efforts have been made to grow high quality $3 \mathrm{C}-\mathrm{SiC}$ film on $\mathrm{Si}$-substrate, the grown $3 \mathrm{C}-\mathrm{SiC} / \mathrm{Si}$ heterojunction experiences crystal defects and film stress at the interfaces due to different thermal expansion coefficients and the lattice mismatch between 3C-SiC and $\mathrm{Si}$ [9], [10]. The crystal defects, mainly stacking faults, as well as film quality can be improved by carbonizing the active silicon surface before the deposition of 3C-SiC [10], [11]. A number of studies have reported that, despite the presence of crystal defects at the interface, $3 \mathrm{C}-\mathrm{SiC} / \mathrm{Si}$ heterojunction show excellent diode characteristics with a large valance band offset (1.7 $\mathrm{eV}$ ) between $\mathrm{SiC}$ and $\mathrm{Si}$ [12]- [14]. As such, the large effective barrier height could be very useful for many applications, such as piezoresistive sensors [6], piezo-Hall devices [15], and biomedical applications [16], where electrical isolation between $3 \mathrm{C}-\mathrm{SiC}$ and $\mathrm{Si}$ is essential.

Silicon carbide based photodetectors are primarily used for UV detection and their peak responsivities are around 260$400 \mathrm{~nm}$ [17]- [19]. Since, 3C-SiC has a smaller band gap $(2.38 \mathrm{eV})$ compared to other $\mathrm{SiC}$ polytypes, typically $3 \mathrm{C}-\mathrm{SiC}$ should show better spectral response in the UV/blue spectral region. Therefore, this study investigates the potential of detecting both ultraviolet and visible photons in the same 3C$\mathrm{SiC} / \mathrm{Si}$ heterostructure. The rectification ratio of the fabricated heterojunction is found to be $1.8 \times 10^{6}$, which is one of the best rectification ratio values for $3 \mathrm{C}-\mathrm{SiC} / \mathrm{Si}$ devices in the literature to date, leading to the improvement in dark current and responsivity. In addition, the insight of the carrier transport phenomena in the proposed heterostructure is discussed in detail based on the analysis of the energy band diagram.

\section{DEVICE FABRICATION AND SETUP}

Employing a Low Pressure Chemical Vapor Deposition (LPCVD) technique, the 3C-SiC (100) film is deposited epitaxially on a Si-substrate $(100)$ at $1000{ }^{\circ} \mathrm{C}$ [20], [21]. The 3C-SiC film is grown to a thickness of approximately 300 $\mathrm{nm}$ with a carrier concentration of $10^{16}-10^{17} \mathrm{~cm}^{3}$. The $3 \mathrm{C}$ $\mathrm{SiC}$ film is patterned using conventional lithography processes to create isolated $3 \mathrm{C}-\mathrm{SiC} / \mathrm{Si}$ heterojunctions and then etched using plasma etching in a LAM 480 system. Following this, a $100 \mathrm{~nm}$ thick oxide layer is deposited on the film utilizing a Hitech LPCVD furnace at $440{ }^{\circ} \mathrm{C}$. The deposited $\mathrm{SiO}_{2}$ will reduce the perimeter leakage around the mesa structure by passivating the $\mathrm{SiC}$ surface. It will also protect the mesa structure exposed $3 \mathrm{C}-\mathrm{SiC} / \mathrm{Si}$ heterojunction area from contaminations and the effects of any further high-temperature processing.

Consequently, more than $90 \%$ of the oxide area is etched, using a buffered oxide etch, from the isolated 3C-SiC top 


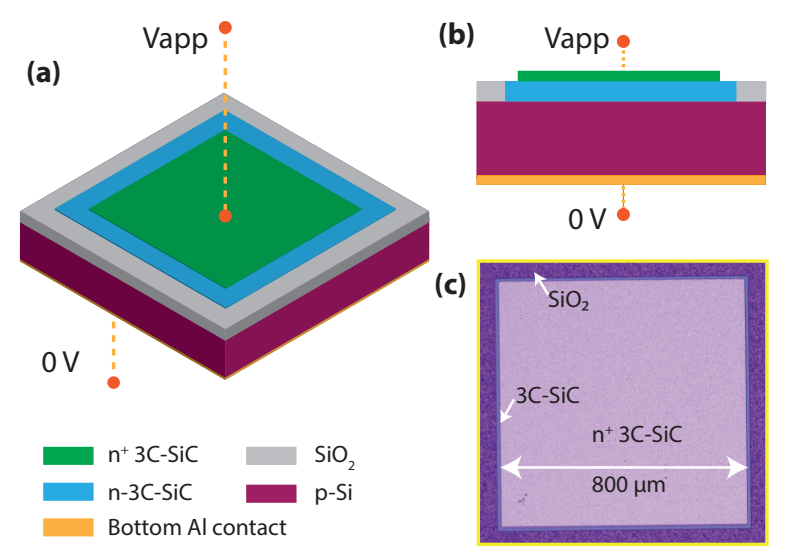

Fig. 1. (a) A schematic and (b) cross-sectional illustration of the proposed $\mathrm{n}-3 \mathrm{C}-\mathrm{SiC} / \mathrm{p}-\mathrm{Si}$ heterostructure; (c) the fabricated heterostructure.

surface to form windows for the deposition of heavily doped $\mathrm{n}$-SiC layer $(90 \mathrm{~nm})$ to create top contacts. To make the bottom contact, the $3 \mathrm{C}-\mathrm{SiC}$ from the back surface is removed by inductively coupled plasma etching and then $\mathrm{Al}$ is sputtered on the exposed $\mathrm{Si}$ as a back contact. The details of the device fabrication steps can be found elsewhere [12]. A schematic and a cross-sectional sketch of the 3C-SiC/Si heterostructure are shown in Figs. 1(a) and (b), respectively. Figure 1(c) shows a microscopic image of the fabricated devices. The currentvoltage characteristics of the heterostructure are measured by a Keithley 2450 SourceMeter. A $637 \mathrm{~nm}$ (Thorlab) and a $375 \mathrm{~nm}$ laser (Nichia) are employed for the photocurrent measurements.

\section{RESULTS AND DISCUSSION}

Figure 2(a) shows the I-V characteristics of the n-3C$\mathrm{SiC} / \mathrm{p}-\mathrm{Si}$ heterojunction in dark conditions and under UVvisible illumination. The ratio of forward and reverse current (in dark conditions) at $+/-2 \mathrm{~V}$ is found to be $1.8 \times 10^{6}$, indicating the superior rectifying behavior of the structure. The ideality factor of the forward bias current is found to be 1.24 , which indicates that the forward current dominates by a diffusion mechanism, but it also consists of a small portion of generation-recombination components. The generationrecombination may result from the $\mathrm{SiC} / \mathrm{Si}$ interface defects. Figure 2(b) shows the excellent repeatable and stable photoresponse of the heterostructure when the light is turned $\mathrm{ON}$ and OFF under both $375 \mathrm{~nm}$ and $637 \mathrm{~nm}$ illuminations. In addition, the linear increasing trend of the photocurrent $\left(I_{p h}\right)$ with illumination intensity indicating that the proposed structure could be used as a self-power photodetector [22]. The device exhibits a relatively fast response and recovery time compared to the reported UV-visible photodetectors [1], [3], [23]. The response time and recovery time are found to be $0.32 \mathrm{~s}$ and $0.36 \mathrm{~s}$, respectively, under $375 \mathrm{~nm}$ illumination, and $0.35 \mathrm{~s}$ and $0.40 \mathrm{~s}$ under $637 \mathrm{~nm}$ illumination. It is expected that the actual device response time will be even faster, considering the time resolution of the illumination source and the I-V measurement instrument. In addition, as observed, the variation in current density is almost insignificant under forward bias conditions
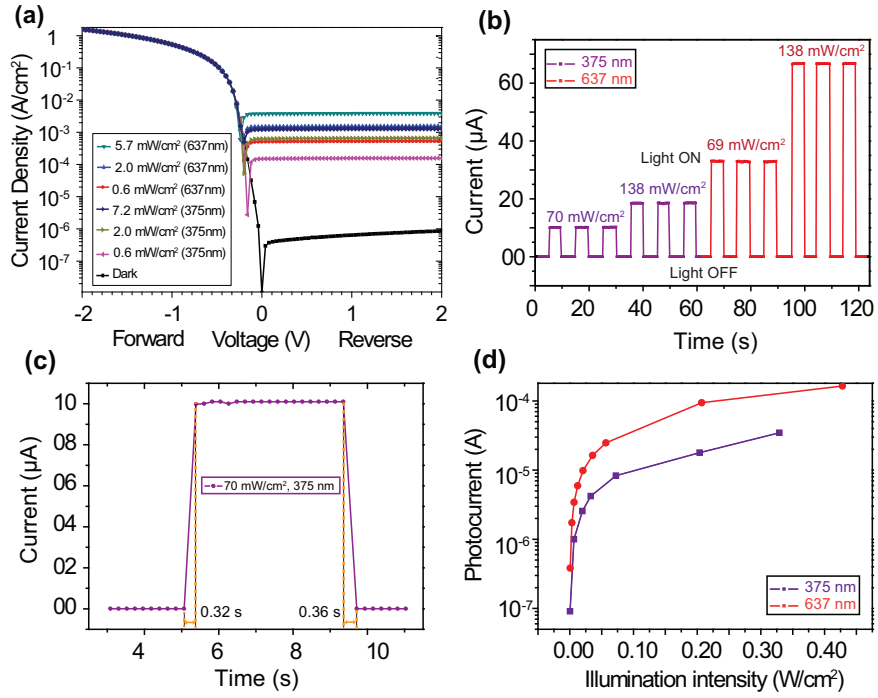

Fig. 2. (a) Current-voltage characteristics of the 3C-SiC/Si heterojunction in dark conditions and under UV $(375 \mathrm{~nm})$ and visible $(637 \mathrm{~nm})$ illumination at different intensities, (b) repeatability of the response, (c) response and recovery time, and (d) photocurrent of the heterostructure as a function of light intensity at a reverse bias voltage of $2 \mathrm{~V}$.

(Fig. 2(a)). However, the reverse current density varied significantly in reverse bias. For instance, the photocurrent density at a reverse bias $(2 \mathrm{~V})$ condition increases about 72 times than that in the forward bias $(-2 \mathrm{~V})$ condition $\left(56 \mathrm{~mW} / \mathrm{cm}^{2}, 637\right.$ $\mathrm{nm})$. Hence, the photodetector is connected in reverse bias conditions to measure the photosensitivity.

Figure 2(d) shows the intensity dependent photocurrents $\left(I_{p h}=I_{\text {Light }}-I_{\text {Dark }}\right)$ under both UV and visible illumination. As observed, the $I_{p h}$ increases with the increase of illumination intensity. Because the carrier generation rate, at a fixed wavelength and under steady state conditions, mainly depends on the incident photon flux intensity and hence more carriers will generate at higher intensities [24], [25]. Moreover, the $I_{p h}$ increases significantly under visible light, which is about 5.3 times higher than that in UV light $\left(0.2 \mathrm{~W} / \mathrm{cm}^{2}, 2\right.$ V). The mechanism behind the photocurrent characteristics at UV and visible light conditions can be qualitatively explained through an energy band diagram analysis, where the band offsets are obtained from [26]. Figure 3(a) shows the energy band diagram of the heterojunction in dark conditions at a reverse bias of $2 \mathrm{~V}$. Due to the lower ratio of hole concentration in $\mathrm{p}$-Si $\left(5 \times 10^{14} \mathrm{~cm}^{-3}\right)$ side to the electron concentration in $\mathrm{n}$-3C-SiC side $\left(10^{16}-10^{17} \mathrm{~cm}^{3}\right)$, the depletion width in $\mathrm{Si}$ is greater than that in $\mathrm{n}-3 \mathrm{C}-\mathrm{SiC}$. As observed, the electrons tunnel from the valance band of $\mathrm{Si}$ to the trap states at the 3C-SiC/Si interface and are followed by thermionic emission to the conduction band of $3 \mathrm{C}-\mathrm{SiC}$, resulting in a small current flow in reverse bias conditions.

Figure 3(b) shows the energy band diagram of the heterostructure under visible $(637 \mathrm{~nm})$ illumination, where the light incidence comes from the top $3 \mathrm{C}-\mathrm{SiC}$ side. Due to the large bandgap of $3 \mathrm{C}-\mathrm{SiC}(2.38 \mathrm{eV})$, the visible light transmits through the top layer and primarily absorbs in the bottom Si-layer, and generates electron-hole (e-h) pairs in Si. The generated electrons and holes move toward the positive and 


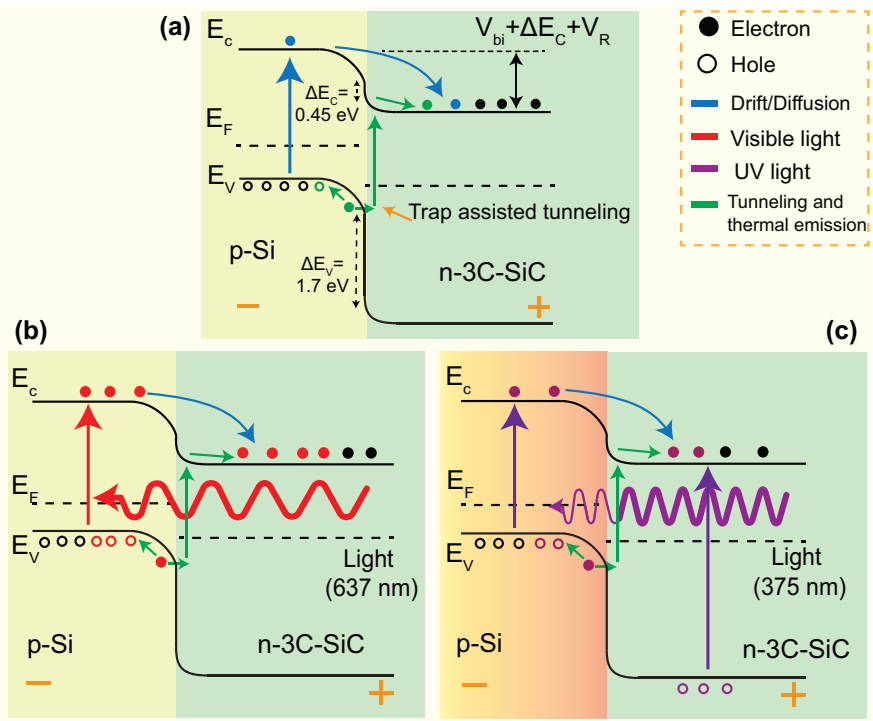

Fig. 3. Energy band diagram of the heterostructure and carrier transport mechanism at reverse bias conditions in (a) dark conditions, and under (b) visible light $(637 \mathrm{~nm})$ and (c) UV light $(375 \mathrm{~nm})$.

negative terminals, respectively, as there is no barrier in reverse bias condition. As a result, the $I_{p h}$ increases significantly under visible light.

On the other hand, under UV (375 nm) illumination, because of the thin $(300 \mathrm{~nm}) 3 \mathrm{C}-\mathrm{SiC}$ layer, a small portion of the incident photons will absorb in the $3 \mathrm{C}-\mathrm{SiC}$ (transmittance $\sim 78 \%$ at $375 \mathrm{~nm}$ ) and remaining photons will reach the bottom p-Si layer (Fig. 3(c)). As the incident photon energy $(3.32 \mathrm{eV})$ is much higher than the bandgap of $\mathrm{Si}(1.12 \mathrm{eV})$, under UV light the photoconversion efficiency of $\mathrm{Si}$ is very low and extra photon energies will be lost as heat within the device [26], [27]. The photogenerated electrons and holes in $3 \mathrm{C}-\mathrm{SiC}$ will move toward the positive and negative terminal, respectively. However, due to a low e-h pair generation under $375 \mathrm{~nm}$ illumination, a lower $I_{p h}$ is observed under $375 \mathrm{~nm}$ light than that under $637 \mathrm{~nm}$ illumination. A thicker 3C-SiC top layer will absorb more UV photons, and therefore, it is expected that a higher $I_{p h}$ will be generated. This effect will be investigated quantitatively in a future study.

The performance of a photodetector can be examined by its responsivity $\left(R_{e}\right)$ at a particular wavelength, which is defined as [28], $R_{e}=I_{p h} / P_{i}=I_{p h} / A . I_{i}$, where, $I_{i}$ is the illumination intensity and $A$ is the device area. Figure 4 shows the responsivity of the fabricated heterostructure at different light intensities. The structure shows a peak responsivity of $10.9 \times 10^{-2} \mathrm{~A} / \mathrm{W}$ and $3.2 \times 10^{-3} \mathrm{~A} / \mathrm{W}$ under the illumination of $637 \mathrm{~nm}$ and $375 \mathrm{~nm}$, respectively $\left(0.5 \mathrm{~mW} / \mathrm{cm}^{2}, 2 \mathrm{~V}\right)$. It is also observed that the responsivity decreases with increasing illumination intensities. The observed phenomenon may attribute to the advantage of low reflectance due to scattering at low intensities, endowing the higher photoconversion efficiency at lower intensities than that in higher intensities [29], [30]. The spectral responsivity of the device (at an intensity of approximately $6.6 \mathrm{~mW} / \mathrm{cm}^{2}$ ) is shown in Fig. 4(b). As observed, the device shows the maximum responsivity

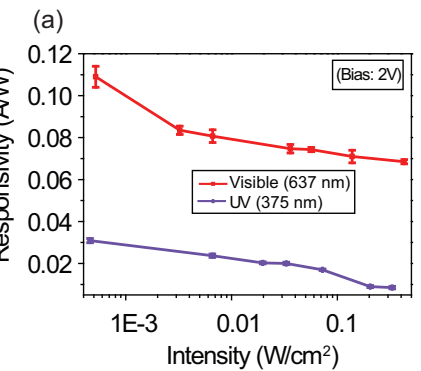

(b)

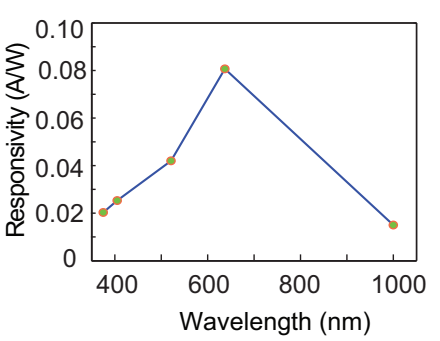

Fig. 4. (a) The responsivity of the $3 \mathrm{C}-\mathrm{SiC} / \mathrm{Si}$ heterostructure under UV and visible illuminations at different excitation intensities and (b) spectral responsivity of the device at an intensity of approximately $6.6 \mathrm{~mW} / \mathrm{cm}^{2}$.

around the red wavelengths, which can be attributed to the optimum photo-current conversion efficiency of Si near these wavelengths [31], [32].

To investigate the advantages of a highly rectifying $3 \mathrm{C}$ $\mathrm{SiC} / \mathrm{Si}$ heterojunction, we also fabricate a heterostructure with low rectification ratio $\left(1.03 \times 10^{3}\right)$. The $I_{\text {Dark }}$ and $R_{e}$ of the device are found to be $7.6 \times 10^{-6} \mathrm{~A}$ and $5.4 \times 10^{-2} \mathrm{~A} / \mathrm{W}$ at a reverse bias of $2 \mathrm{~V}\left(60 \mathrm{~mW} / \mathrm{cm}^{2}, 637 \mathrm{~nm}\right)$, respectively. The results indicate that the $I_{\text {Dark }}$ and $R_{e}$ of the highly-rectifying device are about three orders lower and 1.5 times better, respectively, than that of the device with low rectification ratio. The improvements are attributed to the significant reduction of dark current and increase in the internal field across the junction in the highly-rectifying device.

\section{CONCLUSION}

In summary, we fabricated an $\mathrm{n}-3 \mathrm{C}-\mathrm{SiC} / \mathrm{p}$-Si heterostructure photodetector using a LPCVD technique. The detector shows an excellent rectifying behavior with a rectification ratio of $1.8 \times 10^{6}$ at $\pm 2 \mathrm{~V}$. A peak responsivity of $10.9 \times 10^{-2} \mathrm{~A} / \mathrm{W}$ and $3.2 \times 10^{-3} \mathrm{~A} / \mathrm{W}$ at $2 \mathrm{~V}$ is observed under visible and UV illumination, respectively. The mechanisms behind the different photo-sensitivity under UV and visible illumination are explained via the energy band diagrams. The results reveal that the fabricated $3 \mathrm{C}-\mathrm{SiC} / \mathrm{Si}$ heterostructure can be used to detect both UV and visible light simultaneously, which could be beneficial for wide spectral sensitivity detectors/devices.

\section{ACKNOWLEDGMENT}

This work was performed in part at the Queensland node of the Australian National Fabrication Facility, a company established under the National Collaborative Research Infrastructure Strategy to provide nano and micro-fabrication facilities for Australia's researchers. The diodes were fabricated and provided by the Operations Group, Kien Chaik, Leonie Hold, Glenn Walker and Alan Iacopi, of the Queensland Microtechnology facility at Griffith University. The epitaxial deposition was developed as part of Griffith Universities Joint Development Agreement with SPT Microtechnology, the manufacturer of the Epiflx production reactor. This work was partially funded by linkage grants (LP150100153 and LP160101553) from the Australian Research Council (ARC). 


\section{REFERENCES}

[1] F. Zhang, Y. Ding, Y. Zhang, X. Zhang, and Z. L. Wang, "Piezophototronic effect enhanced visible and ultraviolet photodetection using a ZnO-CdS core-shell micro/nanowire," ACS Nano, vol. 6, pp. 9229-9236, Sep. 2012, doi: 10.1021/nn3035765.

[2] P. J. Lapray, X. Wang, J. B. Thomas, and P. Gouton, "Multispectral filter arrays: Recent advances and practical implementation," Sensors, vol. 14, pp. 21626-21659, Nov. 2014, doi: 10.3390/s141121626.

[3] S. Mridha and D. Basak, "Ultraviolet and visible photoresponse properties of n-ZnO/p-Si heterojunction," J. Appl. Phys., vol. 101, p. 083102, Apr. 2007, doi: 10.1063/1.272480.

[4] Y. K. Fang, S.-B. Hwang, K.-H. Chen, C.-R. Liu, M.-J. Tsai, and L.-C. Kuo, "An amorphous $\mathrm{SiC} / \mathrm{Si}$ heterojunction pin diode for low-noise and high-sensitivity UV detector," IEEE Trans. Electron Devices, vol. 39, pp. 292-296, 1992, doi: 10.1109/16.121685.

[5] W.-C. Lien, N. Damrongplasit, D. G. Senesky, T.-J. K. Liu, and A. P. Pisano, "4H-SiC N-Channel JFET for operation in high-temperature environments," J. Electron Devices Society, vol. 2, pp. 164-167, Sep. 2014, doi: 10.1109/JEDS.2014.2355132.

[6] H.-P. Phan, P. Tanner, D. V. Dao, L. Wang, N.-T. Nguyen, Y. Zhu, and S. Dimitrijev, S., "Piezoresistive effect of p-type single crystalline 3C-SiC thin film," IEEE Electron Device Lett., vol. 35, pp. 399-401, Jan. 2014, doi: 10.1109/LED.2014.2301673.

[7] A. Qamar, H.-P. Phan, D. V. Dao, P. Tanner, T. Dinh, L. Wang, and S. Dimitrijev, "The dependence of offset voltage in p-type 3C-SiC van der Pauw device on applied strain," IEEE Electron Device Lett., vol. 36, pp. 708-710, May 2015, doi: 10.1109/LED.2015.2435153.

[8] A. R. M. Foisal, A. Qamar, H.-P. Phan, T. Dinh, T.-K. Nguyen, P. Tanner, E. W. Streed, and D. V. Dao, "Pushing the Limits of Piezoresistive Effect by Optomechanical Coupling in 3C-SiC/Si Heterostructure," ACS Appl. Mater. Interfaces, vol. 9, pp. 39921-39925,Nov. 2017, doi: 10.1021/acsami.7b12128.

[9] R. Rahimi, C. M. Miller, S. Raghavan, C. D. Stinespring, and D. Korakakis, "Electrical properties of strained nano-thin $3 \mathrm{C}-\mathrm{SiC} / \mathrm{Si}$ heterostructures," J. Phys. D: Appl. Phys., vol. 42, p. 055108, Feb. 2009, doi: $10.1088 / 0022-3727 / 42 / 5 / 055108$.

[10] D. Massoubre, L. Wang, L. Hold, A. Fernandes, J. Chai, S. Dimitrijev, and A. Iacopi, "Vertically conductive single-crystal SiC-based Bragg reflector grown on Si wafer," Sci. Rep., vol. 5, p. 17026, Nov. 2015, doi: $10.1038 /$ srep 17026 .

[11] H.-P. Phan, D. V. Dao, P. Tanner, J. Han, N.-T. Nguyen, S. Dimitrijev, G. Walker, L. Wang, and Y. Zhu, "Thickness dependence of the piezoresistive effect in p-type single crystalline 3C-SiC nanothin films," J. Mater. Chem. C, vol. 2, pp. 7176-7179, Jul. 2014, doi: 10.1039/C4TC01054J.

[12] P. Tanner, A. Iacopi, H.-P. Phan, S. Dimitrijev, L. Hold, K. Chaik, G. Walker, D. V. Dao, and N.-T. Nguyen, "Excellent rectifying properties of the $\mathrm{n}-3 \mathrm{C}-\mathrm{SiC} / \mathrm{p}-\mathrm{Si}$ heterojunction subjected to high temperature annealing for electronics, MEMS, and LED applications,' Sci. Rep., vol. 7, p. 17734, Dec. 2017, doi: 10.1038/s41598-017-17985-9.

[13] S. Guosheng, S. Yanling, W. Lei, Z. Wanshun, L. Muchang, Z. Yongxing, Z. Yiping, L. Jinmin, and L. Lanying, "Heteroepitaxial growth and heterojunction characteristics of voids-free n-3C-SiC on p-Si (100)," Chinese J. Semiconductors, vol. 24, pp. 567-573, 2003.

[14] M. I. Chaudhry, "Electrical transport properties of crystalline silicon carbide/silicon hetero-junctions," IEEE Electron Device Lett., vol. 12, pp. 670-672, Dec. 1991, doi: 10.1109/55.116950.

[15] A. Qamar, D. V. Dao, T. Dinh, A. Iacopi, G. Walker, H.-P. Phan, L. Hold, and S. Dimitrijev, "Piezo-Hall effect and fundamental piezoHall coefficients of single crystal n-type 3C-SiC (100) with low carrier concentration," Appl. Phys. Lett., vol. 110, p. 162903, Apr. 2017, doi: 10.1063/1.4980849.

[16] M. Reyes, C. Frewin, P. J. Ward, and S. E. Saddow, "3C-SiC on Si hetero-epitaxial growth for electronic and biomedical applications," ECS Transactions, vol. 58, pp. 119-126, 2013, doi: 10.1149/05804.0119ecst.

[17] X. Bai, D. Mcintosh, H. Liu, and J. C. Campbell, "Ultraviolet single photon detection with Geiger-mode $4 \mathrm{H}-\mathrm{SiC}$ avalanche photodiodes," IEEE Photonics Tech. Lett., vol. 19, pp. 1822-1824, Oct. 2007, doi: 10.1109/LPT.2007.906830.

[18] E. Monroy, F. Omnès, and F. Calle, "Wide-bandgap semiconductor ultraviolet photodetectors," Semicond. Sci. Technol., vol. 18, pp. 33-51, Mar. 2003, doi: S0268-1242(03)35959-0.

[19] D. M. Brown, E. T. Downey, M. Ghezzo, J. W. Kretchmer, R. J. Saia, Y. S. Liu, J. A. Edmond, G. Gati, J. M. Pimbley, and W. E. Schneider, "Silicon carbide UV photodiodes," IEEE Trans. Electron Devices, vol. 40, pp. 325-333, Feb. 1993, doi: 10.1109/16.182509.
[20] L. Wang, S. Dimitrijev, J. Han, F. Iacopi, and J. Zou, "Transition between amorphous and crystalline phases of $\mathrm{SiC}$ deposited on Si substrate using H3SiCH3," J. Crystal Growth, vol. 11, pp. 4442-4446, Aug. 2009, doi: 10.1016/j.jcrysgro.2009.07.036.

[21] D. V. Dao, H.-P. Phan, A. Qamar, and T. Dinh, "Piezoresistive effect of p-type single crystalline $3 \mathrm{C}-\mathrm{SiC}$ on (111) plane," RSC Adv., vol. 6, pp. 21302-21307, Feb. 2016, doi: 10.1039/C5RA28164D.

[22] P. Lin, X. Q. Yan, Z. Zhang, Y. W. Shen, Y. G. Zhao, Z. M. Bai, and Y. Zhang, "Self-powered UV photosensor based on PEDOT: PSS/ZnO micro/nanowire with strain-modulated photoresponse," ACS Appl. Mater. Interfaces, vol. 5, pp. 3671-3676, Mar. 2013, doi: 10.1021/am4008775.

[23] Z. Zheng, T. Zhang, J. Yao, Y. Zhang, J. Xu, and G. Yang, "Flexible, transparent and ultra-broadband photodetector based on large-area $\mathrm{WSe}_{2}$ film for wearable devices," Nanotechnology, vol. 27, p. 225501, Apr. 2016, doi: 10.1088/0957-4484/27/22/225501.

[24] T. Soga, Nanostructured Materials for Solar Energy Conversion, Elsevier: Amsterdam, pp. 3-43, Dec. 2006.

[25] S. C. Rai, K. Wang, Y. Ding, J. K. Marmon, M. Bhatt, Y. Zhang, W. Zhou, and Z. L. Wang, "Piezo-phototronic effect enhanced UV/visible photodetector based on fully wide band gap type-II $\mathrm{ZnO} / \mathrm{ZnS}$ core/shell nanowire array," ACS nano, vol. 9, pp. 6419-6427, Jun. 2015, doi: 10.1021/acsnano.5b02081.

[26] S. M. Sze and K. K. Ng, Physics of Semiconductor Devies, John Wiley and Sons: New York, 2007.

[27] V. K. Sethi, M. Pandey, and M. P. Shukla, "Use of nanotechnology in solar PV cell," Int. J. Engineering computing, vol. 2, pp. 10003-10006, Apr. 2017.

[28] Q. Yang, X. Guo, W. Wang, Y. Zhang, S. Xu, D. H. Lien, and Z. L. Wang, "Enhancing sensitivity of a single $\mathrm{ZnO}$ micro-/nanowire photodetector by piezo-phototronic effect," ACS Nano, vol. 4, pp. 62856291, Oct. 2010, doi: 10.1021/nn1022878.

[29] L. Brzozowski, V. Sukhovatkin, E. H. Sargent, A. J. SpringThorpe, and M. Extavour, "Intensity-dependent reflectance and transmittance of semiconductor periodic structures," IEEE J. Quantum Electronics, vol. 39, pp. 924-930, Jun. 2003, doi: 10.1109/JQE.2003.813195.

[30] G. J. Kremers, K. L. Hazelwood, C. S. Murphy, M. W. Davidson, and D. W. Piston, "Photoconversion in orange and red fluorescent proteins," Nature Methods, vol. 6, pp. 355-358, Apr. 2009, doi: 10.1038/NMETH.1319.

[31] J. C. Goldschmidt, C. Do, M. Peters, and A. Goetzberger, "Spectral Splitting Module Geometry that Utilizes Light Trapping," Solar Energy Mater, Solar Cells, vol. 108, pp. 57-64, Jan. 2013, doi: 10.1016/j.solmat.2012.09.001.

[32] H. Sai, T. Matsui, T. Koida, K. Matsubara , M. Kondo, S. Sugiyama, H. Katayama, Y. Takeuchi, and I. Yoshida, "Triple-Junction Thin-Film Silicon Solar Cell Fabricated on Periodically Textured Substrate with a Stabilized Efficiency of 13.6\%", Appl. Phys. Lett., vol. 106, p. 213902, May 2015, doi: 10.1063/1.4921794. 